\title{
PerCursos
}

\section{A propósito de Judge Dredd: uma distopia contemporânea}

\section{Resumo}

Passada num ambiente distópico, Judge Dredd é uma obra de HQ que centra a sua atenção em temas como o totalitarismo, autoritarismo, a violência ou os perigos da tecnologia. $O$ estudo aqui apresentado procura olhar para a obra de Wagner e Ezquerra explorando, em primeiro lugar, o universo da personagem Dredd, para depois analisar as duas adaptações cinematográficas $(1995,2012)$ que se lhe seguiram e a forma como estas refletem as ansiedades do seu tempo. Desse modo, o objetivo deste estudo é perceber como Dredd, mas também Mega-City One (local onde se passa a narrativa), têm sido usados enquanto reflexo da contemporaneidade e como forma de denunciar os potenciais perigos de um (futuro) mundo distópico.

Palavras-chave: Juiz Dredd. Distopia. Totalitarismo. Histórias em quadrinhos. Cinema.

\author{
José Duarte \\ Professor na Faculdade de \\ Letras, CEAUL - Universidade de \\ Lisboa. \\ Portugal \\ joseaoduarte@gmail.com
}

\section{Para citar este artigo:}

DUARTE, José. A propósito de Judge Dredd: uma distopia contemporânea. PerCursos, Florianópolis, v. 21, n.47, p. 108 - 129, set./dez. 2020.

DOI: $10.5965 / 1984724621472020108$

http://dx.doi.org/10.5965/1984724621472020108 


\title{
On Judge Dredd: a contemporary dystopia
}

\begin{abstract}
Set in a dystopian environment, Judge Dredd is a comic book that focuses on totalitarianism, authoritarianism, violence, or the dangers of technology. The study presented here seeks to look at the work of Wagner and Ezquerra, exploring, first, the universe of the character Dredd, and then analyzing the two subsequent cinematographic adaptations $(1995,2012)$ and the way they reflect the anxieties of the time. Thus, this study aims to understand how Dredd, but also Mega-City One (the place where the narrative takes place), has been used as a reflection of contemporaneity and as a way of denouncing the potential dangers of a dystopian (future) world.
\end{abstract}

Keywords: Judge Dredd. Dystopia. Totalitarianism. Comics. Cinema. 
"Only those who break the law have anything to fear from me. I am the law and you'd better believe it!" - Judge Dredd

\section{Dredd - o início}

O Juiz Dredd é considerado uma das personagens mais icônicas do universo das HQ, a par de outros, como é o caso de The Punisher ${ }^{1}$, e foi criado pelas mãos de John Wagner (escritor), Carlos Ezquerra (ilustração) e Patt Mills, editor responsável pela sua primeira aparição na revista semanal $2000 A D^{2}$, a 5 de março de 1977 . Os seus dados biográficos ficcionais dão-nos conta de que o Juiz Dredd é Juiz Joseph Dredd, um agente da lei na distópica cidade de Mega-City One, que se estende por grande parte da costa leste dos Estados Unidos da América.

Apesar de ter sido originalmente publicado por uma editora britânica, Judge Dredd chegou a ter uma versão licenciada pela DC nos anos 9033, para além de duas adaptações cinematográficas: a primeira pelas mãos de Danny Cannon (1995) e a segunda por Pete Travis (2012). Essas criações são indício de que Judge Dredd, não pertencendo nem ao Universo DC nem ao Universo Marvel$^{4}$, é tão importante e tão popular quanto as publicações dessas editoras. Contudo, permanece um pouco à margem das mesmas. Esta questão é especialmente relevante tendo em conta o contexto atual em que a indústria de Hollywood, mas não só, tem vindo a adaptar as mais variadas histórias de (super) heróis para a grande (e pequena) tela. Para muitos críticos, e para o público em geral, Judge Dredd não foi bem tratado na primeira adaptação para o cinema e, no caso da segunda transposição para a grande tela, o filme não mereceu a atenção devida por parte

\footnotetext{
${ }^{1}$ A propósito desta questão, sugere-se a leitura de: DUARTE, José; MARTINS, Rita. Punisher: si vis pacem, para bellum. In: GOULART, Michel (org.). Cruzando universos: representações dos super-heróis no tempo presente. São Paulo: Todas as Musas, 2019. p. 123-145.

22000 AD é uma revista de Ficção Científica inglesa publicada atualmente pela Rebellion Developments, mas inicialmente impressa pela IPC Magazines.

${ }^{3}$ A história alternativa licenciada pela DC, que durou cerca de dois anos e teve 18 números, é evidência clara da sua importância no contexto da cultura popular americana, mesmo sendo um trabalho originalmente produzido na Inglaterra. Grande parte das histórias desta versão foi escrita por Andy Helfer, que viria também, em 1995, a publicar Judge Dredd: The Official Movie Adaptation, com ilustração de Ezquerra.

${ }^{4}$ DC Comics e Marvel Comics são duas das maiores e mais importantes editoras de histórias em quadrinhos responsáveis pelo surgimento de super-heróis como Superman, Batman ou Wonder Woman (DC) e Spiderman, Ironman ou Captain America (Marvel).
} 
da crítica, embora tivesse se tornado um objeto de culto comparável a outras grandes obras cinematográficas 5 .

Assim, este ensaio pretende, por um lado, dar conta de quem é Dredd, fazendo uma pequena reflexão sobre a personagem criada por Wagner e Ezquerra, para depois explorar o seu percurso no cinema, examinando as duas adaptações já antes referenciadas. Em ambos os casos, a análise recairá na forma como os filmes espelham, de algum modo, o momento em que são produzidos, em especial porque a história de Judge Dredd, como veremos, aponta para um universo distópico que reflete os problemas e ansiedades do mundo contemporâneo. As três partes em que o estudo se divide tentam, de alguma forma, mostrar o que Dredd representa ou pode representar, mas também indicar as suas contradições enquanto herói que é também a lei.

Para efeitos deste estudo, é usada a ideia de distopia desenvolvida por Gregory Claeys (2017, p. 5) em Dystopia: A Natural History - A Study of Modern Despotism, its Antecedents, and its Literary Diffractions. Neste livro, o autor defende, entre muitas outras ideias, que a distopia, em particular a distopia política, como é o caso de Judge Dredd, é a representação de uma utopia falhada, geralmente associada aos regimes totalitários do séc. XX:

Here it typically means a regime defined by extreme coercion, inequality, imprisonment, and slavery. Often this is described as some concept of collectivism run wild, though some include conformist tendencies in liberal societies which encourage egalitarian repression and intolerance. (CLAEYS, 2017, p. 5)

É também importante não deixar de lado a hipótese de que Judge Dredd pode ser encarado como uma distopia ambiental e uma distopia tecnológica, como veremos, dado

\footnotetext{
5 Sobre este assunto, veja-se, por exemplo, o artigo “Dredd: Why Hollywood won't make a sequel to this Cult Classic", de Michael Payne, publicado no site Undercurrent Atlanta, em que autor refere os vários fãs que o filme tem, para além de uma página de Facebook e uma conta de Twitter com inúmeros seguidores a solicitarem uma sequela ao filme de Pete Travis, em particular pela prestação de Karl Urban como Juiz Dredd. (PAYNE, Michael. "Dredd: why Hollywood won't make a sequel to this cult classic”. Undercurrent Atlanta, [s/d]. Disponível em: http://www.undercurrentatlanta.com/trailers/dredd-why-hollywood-wontmake-a-sequel-to-this-cult-classic/. Acesso em: 10 dez. 2019.)
} 
o estado ruinoso de Mega-City One por causa da guerra e a forma como os juízes se servem da tecnologia para exercer repressão sobre os seus habitantes. Como tal, embora Judge Dredd possa ser olhado principalmente como uma distopia política dado o uso de poder e controle por parte dos juízes, este não deixa de ser uma transposição visual dos perigos da vigilância permanente - que possibilita precisamente a repressão a que aludi acima - resultante de um mundo afligido por atos terroristas, em específico a partir do início do século XXI.

\section{Homem da Lei}

Para compreender Judge Dredd é preciso contextualizá-lo brevemente a partir de duas perspetivas. A primeira está relacionada com o seu momento de publicação e a outra surge como consequência do primeiro. Durante o final dos anos 70, nos anos 80 e início dos anos 90, em especial no território estadunidense, os artistas de HQ começaram a responder com a sua arte em relação ao período em que se encontravam. Os Estados Unidos lidavam, entre muitos outros problemas, com um momento complicado geopolítico e cultural: o país tinha saído de (e perdido) uma guerra (Vietnã) que era contestada em nível nacional e internacional, e na qual milhares de vidas desapareceram, e poucos anos depois sofreu uma forte recessão econômica nos anos de 1980-82. Essa situação, por sua vez, gerou uma enorme contestação do governo e das suas instituições.

Paralelamente, os grandes centros urbanos eram espaços marcados pela violência que aumentava gradualmente. De acordo com Richard Florida (2018), em "The Great Crime Decline and the Comeback of Cities", no início dos anos 90, perto de metade das grandes cidades dos Estados Unidos eram locais violentos, o que não só se devia ao fato da maioria dos bairros estarem abandonados, mas também por serem espaços de concentração de venda de drogas. A “crise urbana” (OREJEL, 2014) que se arrastou em particular durante os anos 70 e início dos anos 80 esteve marcada pela epidemia do “crack", como nota Cummings (2012), mas também por tensões raciais e pela brutalidade policial que, no caso de Judge Dredd, é levada ao extremo, como explicitado por Danny Fingeroth: 
In Dredd's case, the state of violent-American urban crime has gotten to such an out-of-control point that law is now enforced by "Judges" who respond to crimes, stop them, determine who is responsible, then charge those individuals, judge them, pronounce and execute sentence on the lawbreakers, with the entire process often taking mere minutes. They are empowered even-or especially-to carry out capital punishment. (FINGEROTH, 2014, p. 130)

Assim, e não apenas por causa dessa realidade, artistas conhecidos como Frank Miller ou Alan Moore distanciaram-se daquilo que conhecemos como "Silver Age", através da publicação de duas obras fundamentais que viriam a representar uma mudança no universo das HQ. The Dark Knight Returns (Frank Miller, 1986) e Watchmen (Alan Moore, 1986) (re)introduzem personagens anti-heróicas7 que navegam num mundo mais sombrio, violento, distópico e impregnado por um espírito noir que explora um outro lado dos heróis, agora traumatizados por uma nova ordem das coisas.

Essa mudança aconteceu também, de forma mais manifesta, em Hollywood, durante o período já mencionado, o que foi essencial para o surgimento do cinema de ação. Durante os anos 70, 80 e 90, a indústria procurou filmar histórias de heróis que agiam em nome próprio, (anti) heróis com um espírito individualista que, quando todo o resto falhava, e por via da violência, procuravam fazer justiça pelas próprias mãos. Estes eram interpretados por nomes bem conhecidos de todos nós, como Clint Eastwood, Arnold Schwarzenegger, Chuck Norris ou Sylvester Stallone, que são alguns exemplos de heróis musculosos ou com músculo fruto do período político em que Ronald Reagan estava no poder (1981-1989). Em grande parte dos filmes protagonizados por esses atores, o herói era um exemplo de força e determinação, em particular Rambo, que

\footnotetext{
6 "Silver Age", a "idade de prata", que compreende os anos de 1956-69, representou um momento de grande avanço nas HQ e na qual o arquétipo de super-herói predominava. Showcase \#4 (1956), publicada pela DC Comics, é considerada a publicação que deu início a este período.

7 São criações que não respondem à caraterização convencional do super-herói, descrito por Peter Coogan (2009, p. 77) através de três elementos essenciais: uma ideia de missão com um cunho altruísta; uma elevada capacidade tecnológica, superpoderes ou diferentes habilidades (físicas ou psicológicas) e, finalmente, uma identidade dupla. Coogan, no entanto, alerta para o fato de nem todos os super-heróis corresponderem a esta descrição, como será o caso de Dredd.
} 
incorporava de forma mais óbvia alguns desses elementos (TASKER, 2015, p. 142), que a própria versão de 1995 irá recuperar ${ }^{8}$.

Ainda nesse contexto, é necessário sublinhar novamente que Dredd não é um produto norte-americano. Embora a situação política e cultural tenha tido impacto na forma como o personagem foi criado, é importante ter em conta a própria situação na Inglaterra, onde Thatcher lentamente ganhava protagonismo e poder para governar, conseguindo-o finalmente em 1979, dois anos depois da publicação de Judge Dredd, e que durou até 1990. As duras políticas da primeira-ministra, com várias privatizações, diferentes reformas econômicas, e uma ênfase no nacionalismo britânico, tanto nacional como internacional, foram alvo de contestação por parte daqueles que defendiam que o seu sucesso teve um grande impacto em nível social e cultural. Os 11 anos de governo foram marcados por uma elevada taxa de desemprego, agitação social e várias manifestações, indicações de um projeto político que, para muitos (SURIN, 2017), tinha como grande objetivo reforçar o poder do Estado e o seu controle sobre a população apesar do que era assumido publicamente. Como explicita Surin (2017), Thatcher defendia o "Estado mínimo" e necessidade de redução do Estado quando, na verdade, a centralização do poder estatal foi o instrumento fulcral de um governo com um programa que se revelou controlador e, consequentemente, desastroso:

Thatcher used the centralized state to wipe out entire tiers of local government; to spy on her critics; to defang trade unions; to dismantle manufacturing industry; to work-round the boycott of apartheid South Africa; to fight the IRA at a time when many reasonable people, including a handful in her own party, realized that only a negotiated settlement could resolve the Irish "troubles"; to obstruct German reunification; to enrich her husband Denis and their wastrel son Mark; to undertake the neocolonial task of repossessing the Malvinas Islands after they had been seized by Argentina; to reduce spending on education; to administer her programme of privatizing publicly-owned enterprises; to deregulate the financial sector (with the disastrous consequences that have been evident since 2008); and so on. (SURIN, 2017)

\footnotetext{
${ }^{8}$ De notar ainda que Judge Dredd deve bastante, em termos de influência, aos "Exploitation Films" dos anos 70. Estes eram filmes geralmente de baixo-orçamento que exploravam um tema ou uma ideia de forma sensacionalista, com conteúdos considerados tabu, como o sexo, o uso de drogas, nudez e violência gráfica. A maioria destas obras era bastante lucrativa porque dava aos espectadores aquilo que a indústria dos grande estúdios não estava disposta a oferecer.
} 
Judge Dredd, cuja história é passada num futuro distópico em 2099, na cidade ficcional de Mega-City One, onde perduram duras leis, um sistema em que são negados os direitos básicos aos cidadãos, e uma sociedade fraturada, não só traduzia a dinâmica governamental que incluía Reagan, Bush e Thatcher, fruto da visão e experiência de John Wagner, como também pretendia ser uma reflexão sobre governos totalitários, como é o caso particular de Espanha e o regime franquista que, começando na década de 30 do século XX, terminou em 1975. Carlos Ezquerra, responsável pela ilustração de Judge Dredd, era espanhol, viveu sob a ditadura franquista e, ao mesmo tempo, também viveu sob o governo de Thatcher, na Inglaterra, onde assistiu de perto ao movimento punk e à violência policial perante os mineiros que se manifestavam contra as políticas da primeiraministra que, pouco e pouco, tentava enfraquecer o poder dos sindicatos (HUNT, 2018).

Assim, Judge Dredd pode ser lido como uma reelaboração criativa das experiências do escritor e do ilustrador dentro e fora do seu próprio país, o que faz dessa personagem um produto que deriva de várias influências, habitando mundos estranhos, bizarros, pósapocalípticos e distópicos, cuja mensagem se centra no perigo da concentração de poderes e no totalitarismo. Por isso, um dos temas principais de Judge Dredd é a total desconfiança em relação aos que detêm o poder. Essa é também uma das grandes contradições do personagem Dredd - ele é um dos representantes da lei e, no mundo em que habita, a lei é poder, o que legitima o seu modo de ação: brutal, com o poder concentrado num único grupo de elementos, sem o nível mínimo de "autorregulação" (NOGUEIRA, 1998, p. 1), onde júri, juiz e executor se confundem (NOGUEIRA, 1998, p. 2). A figura da lei representada por Dredd assemelha-se assim ao poder autoritário característico de universos distópicos promovidos por governos ditatoriais, o que é visível em vários níveis:

The oddity of the costume, and the design emphasis on fascist chic, pushed Dredd into strange storytelling territory. In some stories he was the hero, in some the villain. Very often, he wasn't the protagonist at all. The genre switched from sci-fi action to horror or comedy, from police procedural to scathing political commentary. (HUNT, 2018) 
Tal como nota lan Hunt na citação acima, o fato de a personagem Dredd enfatizar sua associação a regimes fascistas e autoritários e, nas várias histórias que protagoniza, tanto poder ser herói como vilão, pode funcionar como metáfora para a violência extrema, por via das armas de fogo, bem como para a ordem necessária no caos que se tornou Mega-City One.

Essa constante dualidade apresentada pelas histórias de Dredd leva-nos para o outro modo de contextualizar Judge Dredd e que se relaciona diretamente com uma história já aqui mencionada: The Punisher [O Justiceiro]. O protagonista da HQ The Punisher incorpora ideais outros que o diferenciam, em muitos aspectos, das histórias de super-heróis em que tudo acaba bem. A história, criada por Gerry Conway (escritor), John Romita Sr. e Ross Andru (ilustração), mostra um (anti) herói que se revolta contra o status quo e que decide fazer justiça pelas próprias mãos. Em The Punisher é notória a glorificação da violência, das armas de fogo, do mito do vigilante ${ }^{9}$, e de uma lógica de lidar com os problemas de uma sociedade corrupta que pode ser estabelecida apenas pela força. Dredd, por sua vez, parece surgir como resposta a The Punisher, como indica Di Paolo:

Another response to the Punisher came from overseas. During the 1980s, British comicbook writer John Wagner created Judge Dredd to spoof characters such as the Punisher, and to critique the extreme, militaristic American conservatism of the Reagan administration. Dredd imprisons people for jaywalking, destroys illegally parked cars, beats senseless those who speak disrespectfully to the police, maims thieves, and kills or gives life sentences to anyone who commits any crime more serious than those already mentioned. (DI PAOLO, 2011, p. 129)

\footnotetext{
9 O mito do vigilante é definido por John Cawelti da seguinte forma: "When it becomes evident that the police, the courts, and society in general cannot either protect the innocent or avenge acts of criminal violence, then the vigilante must himself become the law. Since he is only an individual (or a small group without legal authority), his only possible means of securing justice is counter violence. With no court but his own judgment, his only choices are either to destroy the antagonist or let him go. Since failure to destroy the villain will only free him for further evil deeds - the community being either helpless or in some way supportive of the criminal - the hero must confront and destroy the criminals through violence, usually a considerable skill with guns" (CAWELTI, 1975, p. 532).
} 
Desse modo, e como foi referido anteriormente, se por um lado Judge Dredd pode ser encarada como uma obra que analisa a ameaça que os regimes opressivos representam, por outro, também se apresenta como uma crítica ao mundo hiperviolento dos Estados Unidos da América. O personagem tem assim servido a diferentes propósitos, oscilando entre herói e vilão, como Hunt (2018) já antes havia explicitado, sendo usado como comentário político, sátira ou visão de violência.

Não obstante essa ideia de que Judge Dredd surge como resposta a The Punisher, é de notar que os personagens se aproximam em vários aspectos: nenhum pode ser considerado um herói nos termos definidos por Coogan (2009, p. 77); ambos envelhecem ao ritmo das suas histórias (Dredd chega mesmo a aposentar-se em alguns números); ambos estão dependentes da sua força para mudar as coisas; existe uma contradição nas suas ações, i.e., para que algo mude é necessário cometer atos que um herói não cometeria. Punisher fá-lo por via da sua identidade de vigilante - o seu verdadeiro nome é Frank Castle - e Dredd fá-lo através das rígidas regras da lei. Daí que a sua feição nunca seja revelada: ele é a extensão material da permanente vigilância de quem controla MegaCity One, aquele que aplica as regras sem qualquer desvio, existindo até um Livro da Lei que é seguido pelos juízes.

Paralelamente, estando o poder concentrado unicamente nas mãos dos juízes, como aponta Richard Glancey (2015, p. 62), é possível observar um mundo onde não há ninguém acima destes, deixando a cidade à mercê de abusos de poder. Como acrescenta ainda o autor, o mundo de Judge Dredd é caracterizado pela extrema violência e elevadas taxas de crime e o único modo de lidar com tudo isto é eliminar qualquer barreira na separação de poderes: "[...] we see that the judges are performing the role of the legislature (by creating the Book of Law), the executive (by policing the streets) and the judiciary (by sentencing offenders)" (GLANCEY, 2015, p. 62). Essa forma de organização do poder é aceite (ou foi imposta por um sistema) que, preocupado em fazer valer a lei, cria uma sociedade que não é justa ou democrática, e que se reflete em Mega-City One.

A cidade está rodeada por espaço selvagem (“A Terra Amaldiçoada”) e foi concebida como resposta ao aumento exponencial da população nos grandes centros 
urbanos nos E.U.A. ${ }^{10}$. A sua estrutura, com a divisão em setores e edifícios de inspiração brutalista", é súmula de um espaço marcado pela "desestabilização da forma das relações humanas" (NOGUEIRA, 1998), de isolamento ${ }^{12}$ e de falta de sentido de comunidade e de marginalização, onde impera também a tecnologia - responsável por uma grande taxa de desemprego - e as partes dos seres humanos, depois de morrerem, são propriedade do governo e transformadas em consumíveis.

As leis são duras em Mega-City One. A título de exemplo, é ilegal consumir açúcar, bem como outros produtos, como é o caso do café, e existem locais próprios para fumar (Smokatoriums), o que é revelador do modo como as proibições atingem até os aspectos mais básicos do cotidiano. Essa é também a cidade que tem como principal ícone a enorme estátua de um juiz - que se sobrepõe à Estátua da Liberdade - como forma de celebrar a lei, que em Judge Dredd parece servir a dois propósitos diferentes: garantir o precário equilíbrio do espaço urbano, mas também restringi-lo, tornando-a um mal necessário, que compromete a liberdade. Mas essa lei também pode ser corrupta, como apresentado nos dois filmes que analiso em seguida.

\section{Dredd em 1995}

A primeira adaptação de Judge Dredd, dirigida por Danny Cannon, realizador britânico, capitaliza o sucesso dos filmes de ação e dos seus heróis. Apesar de ser

\footnotetext{
${ }^{10} \mathrm{~A}$ população de Mega-City One ultrapassava os 800 milhões de habitantes, (embora tivesse apenas capacidade para 350 milhões) até as "Guerras Atômicas", momento em que esta ficou reduzida a metade.

${ }^{11} \mathrm{~A}$ arquitetura brutalista atingiu o seu auge durante a década de 70 do séc. $\mathrm{XX}$, e depois perdeu a sua influência. Marcada por linhas retas e por uma geometria austera - com construções em concreto - este tipo de arquitetura era usado na construção de edifícios institucionais, tendo como grande objetivo uma função essencialmente utilitária. Foi também usada na construção de edifícios habitacionais para a classe trabalhadora (o grande exemplo seria "The Unité d'Habitation in Marseilles") de Le Corbusier, com apartamentos semelhantes, sem grandes elementos decorativos. Esta viria a perder força no início dos anos 80, uma vez que ficou ligada a um sentimento de decadência - o concreto era um material falível -, dificuldades econômicas, bem como a movimentos totalitários e nacionalistas (STEWART, 2018), em particular os regimes totalitários da primeira metade do Séc. XX, o que faz sentido dentro do contexto de Dredd.

${ }^{12}$ É comum os habitantes de Mega-City One terem ataques psicóticos em que não conseguem distinguir ficção de realidade, fruto da vida acelerada e isolada deste espaço urbano. Para além disso, é notória a forma como grande parte dos habitantes, familiarizados com a presença constante de atos de violência, se tornaram imunes à sua presença, encarando-a mais como um espetáculo de entretenimento do que de horror.
} 
produzido durante a era Clinton, período reconhecidamente de maior abertura cultural e social nos Estados Unidos ${ }^{13}$ em relação, por exemplo, ao período Reagan, reflete muitas das ideias já aqui apresentadas. Um dos elementos centrais nesta questão é a participação de Sylvester Stallone - que anteriormente tinha desempenhado papéis em filmes como Rocky (Joe G. Avildsen, 1976), Cobra (George P. Cosmatos, 1986) ou Demolition Man (Marco Brambilla, 1993) - como grande figura do filme, objeto que resulta majoritariamente numa americanização da obra original ${ }^{14}$. Para além da presença de uma estrela maior de Hollywood, como é o caso de Stallone, o filme é uma grande produção com um elevado orçamento, que procura explorar a importância do herói na cultura americana. Contudo, e como nota o próprio Stallone numa entrevista, Judge Dredd levanta questões pertinentes:

I loved that property when I read it, because it took a genre that I love, what you could term the "action morality film" and made it a bit more sophisticated. It had political overtones. It showed how if we don't curb the way we run our judicial system, the police may end up running our lives. It dealt with archaic governments; it dealt with cloning and all kinds of things that could happen in the future. It was also bigger than any film I've done in its physical stature and the way it was designed. All the people were dwarfed by the system and the architecture; it shows how

\footnotetext{
${ }^{13}$ Em American Cinema of the 1990s: Themes and Variations, editado por Chris Holmlund, Amy Villarejo sintetiza os primeiros anos da era Clinton da seguinte forma: "Clinton represented more than a shift from the right to the left. [...] Clinton brought a message of hope that had wide appeal to the Baby Boom generation [who] had experienced shifts in the possibilities of social and political change from the $1960 \mathrm{~s}$ to the 1990s. [...] Clinton appeared to embody a smooth synthesis of 1960 s radicalism and 1990 s caution. He represented a solution to a number of crises of the moment [...] like the escalating federal deficit, increasing inequalities between rich and poor, the effects of deregulation and privatization [...] like the devastation wrought by HIV/AIDS" (VILLAREJO, 2008, p. 70-71).

${ }^{14}$ Não sendo o propósito deste trabalho fazer uma análise detalhada da presença de Stallone no filme, é de sublinhar que o ator desempenhou um papel importante (e por vezes até desestabilizador) na forma como o filme foi conduzido. $O$ ator queria que Judge Dredd fosse um filme de ação e comédia ao mesmo tempo, quando o tom pretendido não era esse. No entanto, em entrevista à revista Uncut, Stallone reconheceu a oportunidade que perdeu e que podia ter feito melhor, referindo que: "[... ] I do look back on Judge Dredd as a real missed opportunity. It seemed that lots of fans had a problem with Dredd removing his helmet, because he never does that in the comic books. But for me it is more about wasting such great potential there was in that idea; just think of all the opportunities there were to do interesting stuff with the Cursed Earth scenes. It didn't live up to what it could have been. It probably should have been much more comic, really humorous, and fun. What I learned out of that experience was that we shouldn't have tried to make it Hamlet; it's more Hamlet and Eggs" (STALLONE, 2008, p. 118). Danny Cannon, por sua vez, também não ficou satisfeito com os constantes cortes que o filme sofreu para poder ser aceito de acordo com a classificação PG-13.
} 
insignificant human beings could be in the future. (STALLONE, 2008, p. 118)

A adaptação da história de Judge Dredd consegue, por um lado, tirar benefício de uma iconografia particular que, como acrescenta Nogueira (1998), corroborando até as palavras do ator, ao se centrar essencialmente numa arquitetura poderosa e imponente (lembremo-nos de Metropolis de Fritz Lang, 1927) que reflete a força da lei e, por outro, sugere um mundo iminentemente violento, caótico e pós-apocalíptico. As estruturas escolhidas, bem como alguns dos ícones - a águia ou alguns dos desenhos elaborados por Gianni Versace, por exemplo -, relembram sistemas totalitários e fascistas, como é o caso do regime nazista. No entanto, também é importante sublinhar que o filme se aproxima ao grafismo da narrativa original, quer através de detalhes particulares, quer através do uso de determinadas cores ${ }^{15}$.

Ao mesmo tempo, o filme investe - de acordo com outras obras do momento, como é o caso de Blade Runner (Ridley Scott, 1982), Terminator (James Cameron, 1984) ou Robocop (Paul Veerhoven, 1987) -, no poder e perigo da tecnologia. O Juiz Dredd é criado a partir de tecnologia, fruto de trabalho desenvolvido em laboratório, um projeto apelidado de "Janus Project" que também serviu para criar o seu irmão gêmeo e criminoso ${ }^{16}$. Esse projeto resultou numa experiência genética em que o Conselho de Juízes decidiu usar o seu próprio DNA para criar clones de juízes, os quais recebiam falsas memórias para que pensassem que tinham tido uma vida normal. Estes treinavam lado a lado com os outros recrutas que recebiam formação para serem juízes. Dredd e o seu irmão gêmeo, Rico, são produtos dessa experiência, representando também dois caminhos diferentes para o uso da tecnologia: aquilo que pode criar o juiz cumpridor da lei, pode também gerar um criminoso (NOGUEIRA, 1998, p. 5) que quer governar o

\footnotetext{
${ }^{15}$ Note-se, por exemplo, que o realizador do filme, Danny Cannon, chegou mesmo a desenhar um poster de um filme de Judge Dredd em 1987. O filme de 1995 consegue aproximar-se do universo visual da HQ na grande tela quer por via das cores utilizadas - mais vibrantes (amarelo, mas também vermelho) -, quer pelos detalhes da criação do mundo bizarro, altamente tecnológico, e distorcido de Mega-City One, fruto da colaboração do realizador com o designer de produção Nigel Phelps, que trabalhou, entre outros, em filmes como Batman (Tim Burton, 1989).

${ }^{16}$ Seguindo novamente o raciocínio de Claeys, Judge Dredd de 1995 pode também ser encarado como uma distopia tecnológica, na qual a tecnologia e a ciência têm um papel fulcral na destruição da humanidade ou do sistema contra o qual esta se rege.
} 
mundo criando outros juízes como ele. O controle genético em Judge Dredd revela a própria falibilidade do sistema em vários níveis: dos juízes e da sua forma de agir, da lei e da própria Mega-City One.

O segredo do irmão gêmeo é também a razão pela qual Dredd é falsamente incriminado e enviado para a "Terra Amaldiçoada", que no filme é retratada como um local profundamente marginal, onde residem mutantes, exilados, robôs e outros, implicando que a cidade "empurra" todos os que são indesejados, quer por via de uma lei que é demasiado dura, quer por via da forma como está estruturada - nas margens não há qualquer estabilidade. Contudo, esse equilíbrio também não existe dentro da cidade. O sistema tem falhas: não só se transformou numa organização brutal que esmaga o indivíduo, mas também é corrupta internamente.

Quando regressa da “Terra Amaldiçoada”, Dredd descobre juízes corruptos que não cumprem com a sua ética ou conduta, como é o caso de Griffin, responsável pela saída de Rico da prisão, e tenta instaurar de novo a (sua) lei. A cena final, que se centra na luta entre Dredd e Rico, é representativa do antagonismo entre a instalação do caos ou da ordem. Nos laboratórios do "Janus Project", que se situam simbolicamente no topo da Estátua da Liberdade, Dredd consegue matar Rico. O filme termina com os restantes juízes a pedirem a Dredd que se torne juiz-chefe, cargo que este recusa, pois pretende regressar às ruas e continuar o seu papel de agente da lei ${ }^{17}$. O final insiste na figura heróica de Dredd (e Stallone) que restaura simbolicamente o sistema de juízes, embora ele já não seja o mesmo. Conforme assinalado acima, e apesar do filme de 1995 se aproximar visualmente da HQ Judge Dredd, este distancia-se da obra de Wagner e Ezquerra ao centrar-se em demasia na figura icônica de Stallone. Já o filme de 2012 trabalha algumas das questões referidas acima com um maior detalhe e atenção ao universo da HQ, como veremos, mantendo paralelamente algumas das preocupações temáticas do filme de 1995.

\footnotetext{
17 Judge Dredd tira também partido do filme de ação que não está completo sem que o protagonista se apaixone ou pelo menos revele algum tipo de sentimento, no caso, para com a Juíza Hershey (Diane Lane).
} 


\section{Dredd em 2012}

Judge Dredd, de 1995, não foi um sucesso nem em termos de bilheteira nem para a crítica, razão pela qual outros realizadores não tentaram seguir o projeto de adaptação de uma nova história. Foram precisos 17 anos para que se tentasse trazer o juiz de novo para a tela grande, desta vez pela mão do realizador britânico Pete Travis, sendo que a produção coube a Alex Garland. Lançado em 2012, Dredd - o título curto e seco a eliminar o lado paródico e irônico do seu antecessor, que contou com atores como Rob Schneider -, também não foi um êxito de bilheteira, embora tenha sido recebido de forma mais positiva pela crítica $^{18}$. Contudo, o filme rapidamente obteve um estatuto de objeto de culto, muito semelhante ao de Blade Runner, e foi ganhando gradualmente reconhecimento ao longo do tempo.

Filmado majoritariamente na África do Sul (Joanesburgo e Cidade do Cabo), e contando com a participação de Karl Urban como o Juiz Dredd e Olivia Thirlby como Juíza Anderson, Dredd vai mais longe nos temas que aborda, especialmente pelo contexto em que é produzido e a forma como apresenta uma imagem mais negativa do mundo das HQ, como descrito logo no início pelo próprio narrador:

America is an irradiated wasteland. Within it lies the city. Outside the boundary walls, a desert. A cursed earth. Inside the walls, a cursed city, stretching from Boston to Washington D.C. An unbroken concrete landscape. 800 million people living in the ruin of the old world and the mega structures of the new one. Mega blocks. Mega highways. Mega city One. Convulsing. Choking. Breaking under its own weight. Citizens in fear of the street. The gun. The gang. Only one thing fighting for order in the chaos: the men and women of the Hall of Justice. Executioners. Judges. (DREDD, 2012)

\footnotetext{
${ }^{18}$ De acordo com o site The Action Elite, o filme de 1995 teve um orçamento de 90 milhões de dólares e rendeu 115 milhões de dólares a nível internacional. Já o filme de 2012 custou 50 milhões de dólares e teve um retorno de 31 milhões de dólares a nível internacional. Para o reputado crítico Rogert Ebert (1995), por exemplo, o filme de Cannon "nevers slows down enough to make much sense, it's a Blade Runner for audiences with Attention Deficit Disorder", o que fez com que lhe atribuísse duas estrelas em cinco possíveis. Críticos de outras publicações deram-lhe a mesma pontuação, como é o caso de Caryn James no New York Times ou Todd McCarthy na revista Variety. O filme de Travis teve algumas críticas mais ou menos favoráveis - especialmente quando comparado com o seu antecessor -, em particular de publicações especializadas na área, como é o caso da NPR ou IndieWire.
} 
O tom sombrio com que Dredd ${ }^{19}$ descreve o seu mundo sublinha o lado opressivo de Mega-City One, mostrando que os habitantes da cidade não têm forma de escapar às adversidades que são criadas por este mesmo espaço, como nota ainda Krupa:

Mega-City One has a bleached feel to it - there's an oppressive heat, almost as if the entire landscape is still baking from the fallout. The film achieves this effective sense of place largely without elaborate special effects. It's probably a side-effect of the film's relatively modest budget, but it turns out to be a major strength. As it's still recognisably a real city - like Nolan's composite Gotham - it feels like a very real, nightmarish projection of our reality, rather than a distant world coldly fabricated by computer imagery. (KRUPA, 2012)

Apesar de a película ter sido filmada fora dos Estados Unidos, Mega-City One continua a ter semelhanças com outras cidades norte-americanas, nomeadamente Nova Iorque, podendo ser encarada como reflexo (negativo) da crescente população mundial e os problemas que dela surgem (STASIOWSKI, 2016). Simultaneamente, o filme aborda, desde logo, questões como a permanente vigilância e o controle que viriam a marcar a primeira década do século XXI, resultado de políticas antiterroristas pós-11 de setembro.

A cena de abertura do filme atenta, desde logo, para estas questões: a imagem aérea, juntamente com a voz de Dredd, mostram o poder de controle do sistema dos juízes sobre a cidade, evidenciando a ausência de outro sistema de governo. A torre dos juízes é, portanto, o símbolo máximo de poder dentro e fora de Mega-City One, cidade caracterizada por fronteiras/barreiras e espaços (in)diferenciados (os setores).

Este momento conta ainda com Dredd a perseguir um grupo de criminosos num momento que é visualmente violento, quer pela forma implacável como o juiz os persegue, quer pelas imagens: os criminosos estão sob o efeito de uma droga nova, "Slow-Mo", que provoca um efeito de arrastamento do tempo. A cidade é governada pela violência, pela insegurança e pela criminalidade, mas também pelo ambiente opressivo da lei, que a gere com mão de ferro, o que evidencia uma sociedade danificada

\footnotetext{
${ }^{19}$ A corroborar a imagem mais sombria do filme de 2012, Dredd usa um terno com tons mais escuros que o personagem do filme de 1995. Para além disso, e fazendo justiça à história original, Karl Urban nunca tira o capacete, o que faz dele um agente ainda mais temível.
} 
em nível social e estrutural, notório, por exemplo, no modo como o próprio espaço urbano está organizado.

Por um lado, há o departamento dos juízes, que representa a ordem estabelecida, que é moralmente ambígua com juízes corruptos, mas não só. Enquanto representante da lei, Dredd é obcecado com o cumprimento das regras, o que o impede de compreender a realidade social que o rodeia, tornando-o, de alguma forma, uma figura desumana, reflexo de um governo essencialmente preocupado com vigilância e segurança e que ignora as necessidades reais da sua população. Por outro lado, a divisão da cidade em áreas, blocos e gigantes edifícios é ilustrativa do modo como o espaço urbano cria geografias de exclusão. E é aqui que Peach Trees, local onde se passa grande parte da ação, tem um papel importante.

Esse complexo - influenciado pela arquitetura brutalista e por obras como High Rise (1975), de J. G. Ballard - é em si mesmo uma cidade com estruturas e hierarquias específicas, pois nela coexistem diferentes pessoas e negócios. Construído à imagem de guetos dos quais não há saída, principalmente quando a alternativa apresentada pelos juízes parece ser apenas uma, Peach Trees é governado por Ma-Ma (Lena Headey), que controla o tráfico de "Slow-Mo" na área e que funciona aqui como grande antagonista de Dredd. Não só Ma-Ma é uma mulher, como é produto da marginalização imposta pelo sistema e pela cidade. Forçada a trabalhar como prostituta, Ma-Ma sofreu inúmeras experiências traumáticas que se refletem no modo psicótico e violento com que age enquanto líder da sua gangue ("Ma-Ma Clan”), que controla agora a área de Peach Trees.

O edifício, como nota Stasiowski (2016, p. 87), duplica a incessante claustrofobia já evidenciada pela própria mega cidade. A megaestrutura de Peach Trees, desenhada para proteger os habitantes em caso de ataque nuclear, é fechada sobre si mesma e controlada por Ma-Ma. Desse modo, e como acrescenta ainda o autor, o edifício revela os dois lados do poder e, acima de tudo, da opressão. De um lado, o poder dos juízes e, do outro, o de Ma-Ma. O fato de ela se encontrar no topo do edifício e, a partir daí, controlar toda a sua operação, concede-lhe uma posição, de algum modo, semelhante a dos juízes, o que intensifica a ideia de estarmos perante um mundo esmagador e sem saída. Mas Dredd, à semelhança do filme de Cannon, também acusa o sistema: enquanto sobe Peach 
Trees de forma a eliminar Ma-Ma, o juíz é confrontado com outros juízes que são corruptos e que revelam um sistema falido. Aliados à líder da gangue, estes são a prova de um sistema que, sem qualquer tipo de regulação, não só se torna perigoso como também não cumpre com os seus próprios códigos.

Este último elemento é, como sublinha Julian Darius (2012), essencial para compreender a forma como o cinema tem vindo a explorar a corrupção nas grandes sociedades, mas também o papel do (super) herói e das suas ações. Após matar Ma-Ma, Dredd continua imperturbável no seu caminho enquanto agente da lei, mas agora com o conhecimento de outros problemas do sistema que ele próprio representa, o que pode significar uma pequena alteração nos seus valores. De acordo com Darius (2012), Dredd no final reporta que Anderson passou no teste enquanto recruta, o que não é bem verdade.

Esta pequena mentira representa uma quebra do seu código de conduta e, por isso, do código de conduta dos juízes. Contudo, também significa uma abertura por parte do juiz, que já não se rege única e exclusivamente pela lei, uma vez que Anderson representa, na história, uma alternativa ao implacável sistema de Mega-City One por, de algum modo, parecer compreender os seus problemas reais. Essa leitura, passível de ser contestada, apresenta um caminho mais sutil que o primeiro filme: o herói regressa ao sistema, mas agita os seus alicerces por dentro.

\section{Conclusão: “Juiz, Júri e Executor”}

O Juiz Dredd é uma personagem complexa e paradoxal que nem sempre teve o reconhecimento que lhe é devido, em especial no que toca às adaptações à tela de cinema. Embora estas não tenham tido grande sucesso, são exemplificativas da forma como a história do juiz tem sido usada para explorar temas e tensões centrais ao momento histórico em que cada uma foi elaborada. Criado em 1977, como HQ, o relato de Judge Dredd foi usado inicialmente como metáfora para uma sociedade em ebulição que se mostrava cada vez mais opressora e injusta e, como tal, distópica. 
Da cultura norte-americana obcecada com violência, guerras e armas, à repressão do governo de Thatcher, passando por referências a regimes totalitários, mas apontando para problemas do futuro, a criação de Wagner e Ezquerra atenta para a opressão que deriva do controle e exercício do poder. Quer o filme de 1995, quer o de 2012 examinam essas dimensões de formas mais ou menos semelhantes. Embora a criação de Cannon se desvie um pouco do tom da história original, e tire partido do cinema de ação dos anos 70, 80 e 90, esta procura olhar para os efeitos potencialmente nefastos do uso da tecnologia e o controle político e social que esta permite, o que, por sua vez, também nos leva ao filme de 2012.

Assim, os 17 anos que separam ambas as criações não fazem com que as duas adaptações distem radicalmente uma da outra, pois ambas respeitam os temas centrais da narrativa original. Se Judge Dredd responde a um período conturbado dos Estados Unidos e da Inglaterra, o filme de 2012 é construído em torno das várias consequências sociais e políticas que resultaram, por exemplo, da luta contra o terrorismo e a novas formas de "violência, restrição e [...] controlo" (ORPANA, 2014, p. 302)20. Dredd explora também as crescentes disparidades na sociedade contemporânea e afigura-se como uma obra cada vez mais atual, em que a cidade se torna um espaço gerador de desigualdades sociais, tais como a pobreza, condições de vida decadentes, corrupção e falta de oportunidade (URICCHIO, 2010, p. 120).

Finalmente, e corroborando a minha proposta inicial em relação à importância e atualidade de Judge Dredd, é de salientar que o protagonista irá surgir numa nova adaptação para televisão com data ainda a determinar. Para além de outras duas adaptações em webseries (Judge Dredd: Cursed Edge, 2013, fan film dirigido por Oliver Hollingdale e Judge Dredd: Superfiend, 2014, série animada produzida por Adi Shankar), produções de baixo custo, Judge Dredd: Mega-City One, pela mão do produtor Brian Jenkins, será lançado brevemente. Apesar das poucas informações ainda disponíveis relativamente a esta nova vida dada a Dredd, os rumores indicam que, em julho de 2018, o

\footnotetext{
20 Neste artigo, o mesmo autor chega mesmo a referir que Dredd é um filme que também espelha as estratégias políticas da guerra contra a droga iniciada dos anos do governo Reagan, algo que foi referenciado no início deste estudo.
} 
episódio piloto foi gravado (ASHURT, 2018) e que a série pertencerá à Netflix (ainda a confirmar).

Judge Dredd: Mega-City One, de acordo com a notícia publicada pela DigitalSpy e outros sites, será uma série com grande influência do filme de 2012 - até porque se fala de Urban novamente para o papel de Dredd -, mas também tentará aproximar-se mais do universo da narrativa original. Sendo uma série de televisão, é possível prolongar as muitas histórias que Judge Dredd tem para contar e, simultaneamente, expandir outros universos, o que talvez não pudesse acontecer no cinema. Sinal dos tempos que atravessamos, quer comercialmente, quer em nível cultural e político, não é de estranhar que Dredd regresse, dado o sucesso de muitas outras séries com o mesmo tom (incluindo The Punisher, 2017-2019, criada por Steve Lightfoot), mas igualmente pelo momento conturbado que atravessamos, com grandes movimentações humanas, construções de muros, desigualdades sociais, pandemias, crises econômicas e a ascensão de homens (intolerantes) que podem abusar da sua posição de poder. Perante tudo isso, Judge Dredd nunca permaneceu tão atual.

\section{Referências}

STALLONE, Sylvester. Sylvester Stallone interviewed. Uncut \#131, p. 118, abr. 2008.

ASHURT, Sam. Judge Dredd: Mega-City One TV series on Netflix starring Karl Urban release date, cast and everything you need to know. He is the law.... DigitalSpy, 9 ago. 2018. Disponível em: https://www.digitalspy.com/tv/a837878/judge-dredd-tv-mega-cityone-karl-urban-plot-netflix-release-datel. Acesso em: 10 dez. 2019.

CAWELTI, John G. Myths of violence in american popular culture. Critical Inquiry, Chicago, v. 1, n. 3, mar. 1975. Disponível em:

https://www.jstor.org/stable/pdf/1342829.pdf?refreqid=excelsior\%3A0321114fa52bo78a03a fedd7c9784dbc. Acesso em: 10 jul. 2019.

CLAEYS, Gregory. Dystopia: a natural history - a study of modern despotism, its antecedents, and its literary diffractions. London: Oxford University Press, 2017.

COOGAN, Peter. The Definition of the Superhero. In: HEER, Jeet; WORCESTER, Kent (eds.) A comics studies reader. Jackson: University Press of Mississippi, 2009. p. 77-93. 
CUMMINGS, Alex Sayf. Did the broken windows theory work? Tropics of Meta, 14 mar. 2012. Disponível em: https://tropicsofmeta.com/2012/03/14/did-the-broken-windowstheory-work/. Acesso em: 8 dez. 2020.

DARIUS, Julian. Dredd as a violent morality play. Sequart Organization, 24 set. 2012. Disponível em: http://sequart.org/magazine/15754/dredd-as-violent-morality-play/. Acesso 10 dez. 2019.

\section{PAOLO, Marc. War, politics and super-heroes: ethics and propaganda in comics and} films. Jefferson: McFarland, 2011.

DREDD. Direção: Pete Travis. Produção: DNA Films, Peach Trees, Rena Films. Intérpretes: Karl Urban, Olivia Thirlby, Lena Headey, 2012. (95 m.). EBERT, Roger. Judge Dredd. RogerEbert.com, jun. 1995. Disponível em: https://www.rogerebert.com/reviews/judgedredd-1995. Acesso em: 10 dez. 2019.

FINGEROTH, Danny. Superman on the couch: what superheroes really tell us about ourselves and our society. London: Continuum, 2004.

FLORIDA, Richard. The great crime decline and the comeback of cities. Bloomberg City Lab, 26 jan. 2018. Disponível em: https://www.bloomberg.com/news/articles/2018-0116/understanding-the-great-crime-decline-in-u-s-cities. Acesso em: 7 dez. 2020.

GLANCEY, Richard. I am the law teacher! an experiential approach using Judge Dredd to teach constitutional law. In: GIDDES, Thomas (ed.). Graphic justice: intersections of comics and law. London: Routledge, 2015. p. 54-71.

HUNT, Ian. Fascist Spain meets British punk: the subversive genius of Judge Dredd. The Guardian, 3 out. 2018. Disponível em: https://www.theguardian.com/commentisfree/2018/oct/03/judge-dredd-carlos-ezquerra Acesso em: 10 dez. 2019.

NOGUEIRA, Luís. Judge Dredd: homem-lei. www.bocc.ubi.pt, 1998. Disponível em: http://www.bocc.ubi.pt/pag/nogueira-luis-judge-dredd.pdf Acesso em: 17 dez. 2018.

ORPANA, Simon. The law and its illicit desires: transversing free market claustrophobia and the zombie imaginary in dredd 3-D. Review of Education, Pedagogy, and Cultural Studies, v. 36, n. 4, p. 298-319, sept. 2014. Disponível em: https://www.tandfonline.com/doi/pdf/10.1080/10714413.2014.938568?needAccess=true Acesso em: 6 dez. 2020. 
OREJEL, Keith. What Robocop Tell Us about the Neoliberal City, Then and Now. Tropics of Meta, 24 mar. 2014. Disponível em: https://tropicsofmeta.com/2014/03/24/what-robocoptells-us-about-the-neoliberal-city-then-and-now/. Acesso em: 8 dez. 2020.

STASIOWSKI, Maciej. Film and the urban nightmare: Pier Vittorio Aureli's CityArchipelagos as urbanities woven from media images in Pete Travis' Dredd and Christopher Nolan's the dark knight rises. In: CLIFT, Edward M.; GUARALDA, Mirko; MATTES, Ari (eds.). Filming the City: urban documents, design practices and social criticism trough the lens. Bristol: Intellect, 2016. p. 79-93.

STEWART, Jessica. Brutalism: What Is It and Why Is It Making a Comeback? My Modern Met, 4 dez. 2018. Disponível em: https://mymodernmet.com/brutalist-architecture/. Acesso em: 10 dez. 2019.

SURIN, Kenneth. Authoritarian populism: viewing trump, reviewing thatcher. Counter Punch, 7 feb. 2017. Disponível em: https://www.counterpunch.org/2017/02/07/authoritarian-populism-viewing-trumpreviewing-thatcher/. Acesso em: $10 \mathrm{dez} .2019$.

TASKER, Yvonne. The Hollywood action and Adventure film. Chichester: John Wiley \& Sons, 2015.

THE PUNISHER. Criação: Steve Lightfoot. Produção: Netflix. Intérprete: John Bernthal, C2017. (1.374 min.)

URICCHIO, William. Batman's Gotham City ${ }^{\mathrm{TM}}$ : style, ideology and performance. In: ARHENS, Jorn; METZNER, Arno (eds.). Comics and the city. London: Continuum, 2010. p. 119-132.

VILLAREJO, Amy. Movies and the politics of autorship. HOLMLUND, Chris (ed.). American Cinema of the 1990s: themes and variations. Piscataway: Rutgers University Press, 2008. p. 70-91.

Recebido em: 11/05/2020 Aprovado em: 18/12/2020

Universidade do Estado de Santa Catarina - UDESC Centro de Ciências Humanas e da Educação - FAED revistapercursos@gmail.com 